\title{
The Hydraulic Power Generation and Transmission on Agricultural Tractors: feasible architectures to reduce dissipation and fuel consumption - Part 2
}

\author{
Paolo Casoli $^{*}$, Barbara Zardin ${ }^{2}$, Salvatore Ardizio ${ }^{1}$, Massimo Borghi ${ }^{2}$, Francesco Pintore ${ }^{3}$, Davide Mesturini ${ }^{4}$ \\ ${ }^{1}$ Department of Engineering and Architecture, University of Parma, 43124 Parma, Italy. \\ ${ }^{2}$ DIEF-Engineering Department Enzo Ferrari, via. P. Vivarelli 10, 41125, Modena, Italy \\ ${ }^{3} \mathrm{CNH}$ Industrial Italia - Viale delle Nazioni 55, 41122 Modena, Italy \\ ${ }^{4}$ Walvoil S.p.A. - Via Adige 13/D, 42124 Reggio Emilia (Italy)
}

\begin{abstract}
Increasing interest in reducing pollutant emissions and fuel consumption of off-road vehicles has led to research alternative systems that aim to reduce the power dissipations of the hydraulic circuits. This work presents the advantages of few alternative solutions for a hydraulic high-pressure circuit of a medium-size tractor. The standard high-pressure circuit is a typical multiusers load sensing system that uses a single variable displacement pump to feed: steering, trailer brake, rear remotes, hitch and suspension. The alternative architectures have been simulated and compared in terms of mechanical energy consumption. In particular, the steering has been separated from the circuit, it has been actuated by means of a dedicated pump moved by an electric motor, in this way the priority valve could be removed and losses due the pressure compensators are reduced. A further architecture based on the insertion of the LS signal conditioner was studied. The results show that relevant energy saving can be achieved with the new alternative architectures; the physical prototyping of the most promising solutions will be realized as the next step of the project.
\end{abstract}

\section{Introduction}

Fuel consumption reduction and pollutions limits are increasing requirements also for the manufacturers of off-road vehicles; the target is to comply with the strengthening regulations without compromise the performance and reliability of the machine. Many researchers have investigated alternative solutions for excavator, in [1,2] an overview of hydraulic system improvements was given through application of new system solutions, layout optimization, implementation of energy recovery equipment. Potential and/or kinetic energy can be recovered from the boom motion and from the swing drive as reported in [3-5]. To investigate alternative solutions mathematical models of the standard system, have to be developed to create a starting point for modelling and evaluate further solutions.

In [6-12] a recovery of the potential energy from the boom was investigated through the development of mathematical models of both standard hydraulic circuit and hybrid hydraulic circuit; experiments have confirmed the fuel consumption reduction feasible [13]. The mathematical model approach is normally based on a lumped parameter approach that permits to reduce the simulations run time of the whole circuit permitting a wide investigation of different solutions, and the utilization of optimization algorithm. Different mathematical approach can be followed when the target of the modelling is the component optimization of detailed aspects as reported in [14-20].

A growing interest in many areas of applications is in replacing traditional valve-controlled hydraulic actuation systems [21-24]. Many researchers are focused on the investigation of the advantages of pump-controlled cylinder drives respect to conventional hydraulic systems. In $[25,26]$ authors proposed different architectures for pump controlled hydraulic cylinder with self-locking capability. In [27] is presented a literature review about earliest concepts based on fixed and variable displacement pumps and newer solutions based on variable-speed electric drives.

*Corresponding author: paolo.casoli@unipr.it 
In the field of off-road vehicles, the agricultural tractors present hydraulic circuit normally based on Load Sensing systems that permit the reduction of the number of pumps in the system but introduces the disadvantage of power losses incurred by throttling. Focusing on the tractor studied in this research, a fixed displacement pump boosts the main variable displacement pump, which feeds steering, trailer brake and auxiliary utilities, such as rear remotes, rear hitch [28] and front suspension. A double stage priority valve controls the steering and the trailer brake. The fixed displacement pump also controls the filtration and cooling system.

The traditional circuit was previously modelled by Zardin et al. [29-33] and the mathematical model has become the base for investigating the losses distribution through the hydraulic circuit and implementing new layout circuit solutions.

The approach followed is to investigate the energy saving obtainable separating the users and reducing the pressure drop through the control valves. In particular, the hydraulic steering has been separated by the circuit and actuated by means a fixed displacement pump powered by an electric motor at variable speed. This solution permits to reduce the number of the contemporary users and to remove the first stage of the priority valve; the mechanical energy saving obtainable respect to the traditional circuit has been evaluated.

An easier solution to reduce the fuel consumption, is to control the pump margin when possible, this issue requires a control strategy that consider the instantaneous users' needs. This solution has been investigated following an approach that permits to keep the pump displacement controller unchanged thus permitting an aftermarket modification of the circuit.

A new LS signal conditioner has been presented, this device receives the LS signal as input and returns at the output a modified signal called conditioned load sensing. In this device, a modulating pilot pressure, electrically controlled, permits either change or leave unchanged the LS signal transmitted to the pump displacement controller.

Since the conditioned load sensing signal could be different from the starting LS signal and the pump control system will add an unchanged pump margin value, a pressure drop changed at the distributor cursor is obtained. This device is electrical controlled, therefore control strategy based on the instantaneous users' needs can be implemented. This paper presents the results found in terms of the mechanical energy saving obtainable [29, 30, and 33].

\section{Description of the circuit and its modelling}

The standard circuit of the agricultural tractor consists of a filter, pumps, a double stage priority valve, steering, trailers brake, rear remotes and rear hitch. The circuit is a typical closed center load sensing multi-user system (CCLS). The power supply group has two pumps: the first with a variable displacement that feeds the aforementioned users, the second is a fixed displacement pump that has the function of boosting the variable displacement pump, supplying the lubrication line and function of filtering and cooling the fluid, Figure 1a. The pump flow compensator determines the pump pressure margin for this system. The main pump has been modeled as a black box component, while the two compensators are modeled as white-box model using the AMESim $^{\odot}$ Hydraulic Component Design library.

The priority valve has two stages and must guarantee the flow rate to the tractor users, in the following order of priority: steering, trailer brake and auxiliary services, such as the rear remote controls. The priority valve has two spools: the main spool (MS) for steering and the secondary spool (SS) for trailer break and other users. The priority valve has integrated shuttle valves to select the highest load pressure signal to be sent to the pump as load pressure feedback, Fig. 1b. Trailer brake valve (TB) has instead the task of managing the pressure signal generated by the brake pedal and to provide the pressure for the parking brake of the tractor; since it does not involve high power consumption, it has been not taken into account into this work.

The steering system consists of a dynamic hydrostatic guide unit, equipped with a closed center and reactive rotary valve and two orbital motors that regulate the flow rate to be sent to the steering actuator, as shown in Fig 2a. The auxiliary utilities are placed in the rear part of the tractor divided into five sections of electro-hydraulic remote-control distributors in a modular architecture (EHR). Figure $2 b$ shows the scheme of a single distribution section. The pilot pressure of the main pilot proportional control valve is selected through two electric valves; the measured flow rate supplied to the user corresponds to the degree of opening of the spool. A local pressure compensator is placed upstream of the main proportional control valve to ensure control. In addition, there are two pilot valves with blocking control provide the user with a non-return control. Finally, a shuttle valve selects the maximum load sensing pressure of the load to be returned. 


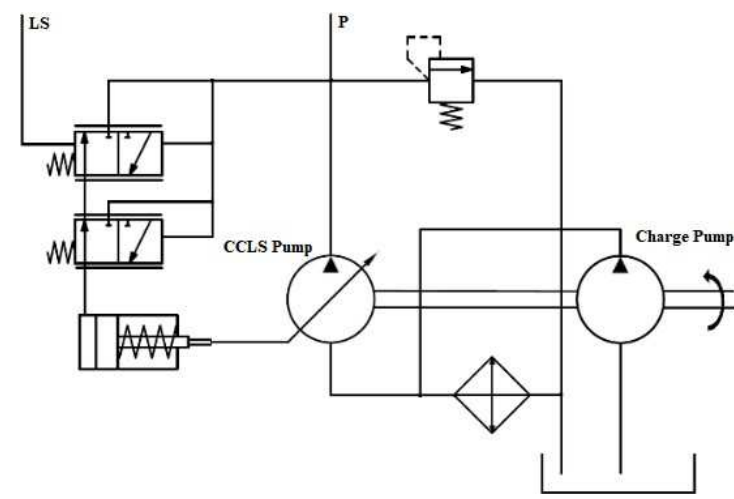

(a)

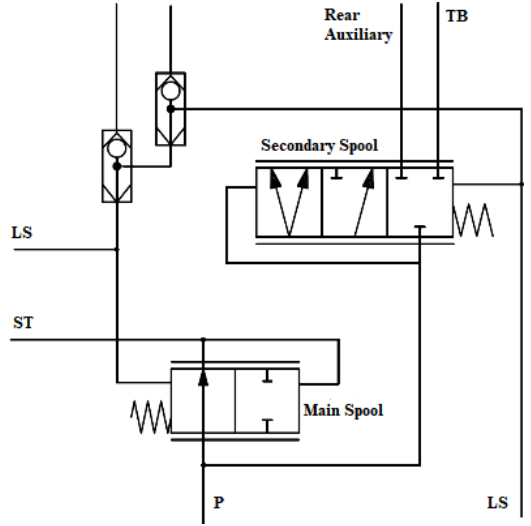

(b)

Fig. 1. Hydraulic scheme of power supply unit (a) and of priority valve block (b)

The rear hitch consists of two hydraulic cylinders in parallel; the control block is directly connected to the rear remote controls. It includes two electro-hydraulic valves, one for lowering the control, which occurs by gravity and therefore does not involve the flow of the pump, and the other for lifting, also pre-compensated [37].

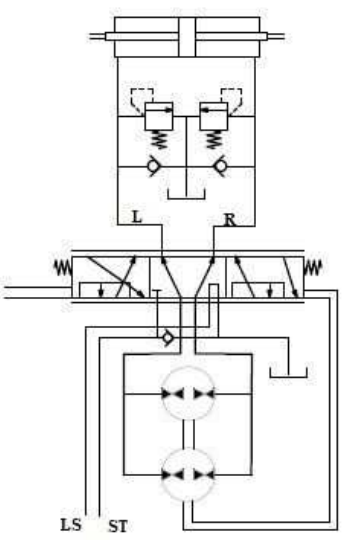

(a)

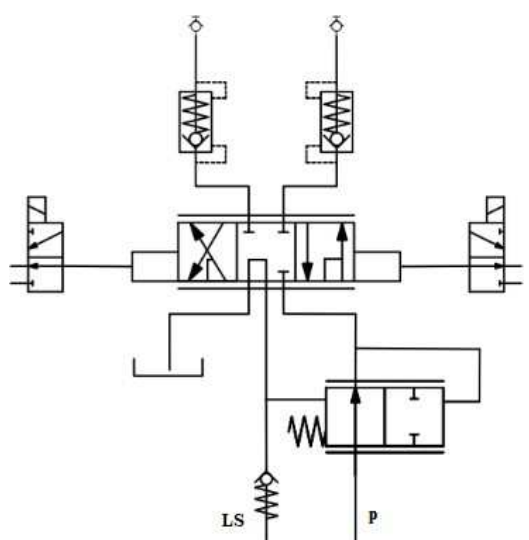

(b)

Fig. 2. Hydraulic scheme of the steering (a) and of EHR section (b)

The remote controls and the connection are served by a single hydraulic line connected to the secondary spool of the priority valve. The pressure drops of the pipes have been included in the models according to the flow rate, starting from the collected experimental data. The model was developed in Simcenter AMESim ${ }^{\odot}$ environment, Fig. 3 and details about this model can be found in [29-34]; the availability of this model, supplyed by CNHi, has been the starting point for investigating the losses distribution through the hydraulic circuit and implement new layout circuit solutions. 


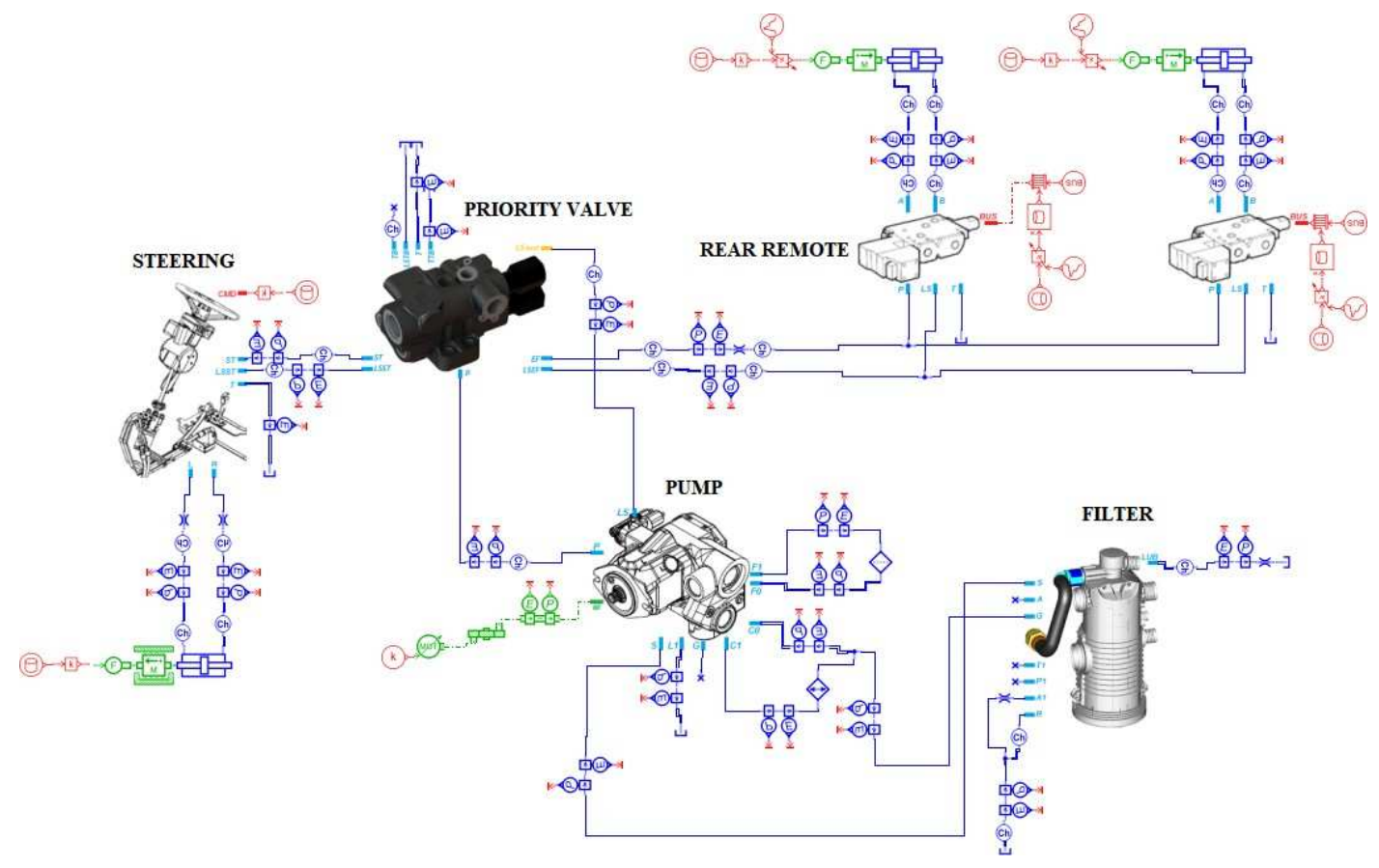

Fig. 3. AMESim ${ }^{\odot}$ sketch of the standard hydraulic circuit

\section{Experimental data acquisition with the standard hydraulic circuit}

The standard circuit of the tractor was characterized through experimental tests conducted by IMAMOTER CNR, and the data were post-processed and analyzed. Tests were done at different engine speed and load conditions, involving steering and rear utilities, either separately or simultaneously. Machine was equipped with flow rate, pressure and LVDT sensors, to monitoring all the variables of interest and the experimental data were acquired considering steering, remotes and trailer braking operations.

The tests were carried out performing steering cycles with aim of keeping controlled and repeat-able steering wheel movements in a green grass wet. The tests investigated the following condition: front weight with $870 \mathrm{~kg}$ (front ballast); lifting and lowering plow with 3 plowshares; revolution of the plow. The steering was operated trying to maintain the same rotation speed while the plow was raised and turned and finally lower it. Data collected were previously used as input for the simulation of the standard architecture to accurately tune and validate the model.

\section{Model validation and energy consumption analysis}

In Fig. 4, a comparison between experimental data and simulation results is reported, with reference to an experimental End-field test. In this test, there is the operation of a section of the rear remote controls to perform the revolution of the rear tool, and moreover, the steering is in operation. The simulation time and the values of pressure and of flow rate were normalized between 0 and 1.

The previously validated standard model represents the reference for the evaluation of performance and consumption. An energy analysis has been performed to identify the dissipative components of the standard circuit (STD). In Table 1, all the energy values have been divided by a reference value for confidential reasons. The reference value adopted, for all the cases considered, is the hydraulic energy provided by the main variable displacement pump in the standard circuit configuration, during the duty cycle reported in Fig. 4. The hydraulic energy users are the energy required by the steering user and those on the EF line, i.e. the rear remotes. The greatest energy demand is linked to the EF line. In fact, the overall demands of the EHR valves is 0.62 respect 0.26 requested from the steering. On the EHR valve, there are losses associated with a value of 0.27 , the remaining 0.35 is available for the actuator.

For the steering, the energy demand is 0.26 , while the losses are 0.08 . Significant losses, 0.12 , occur through the priority valve. 


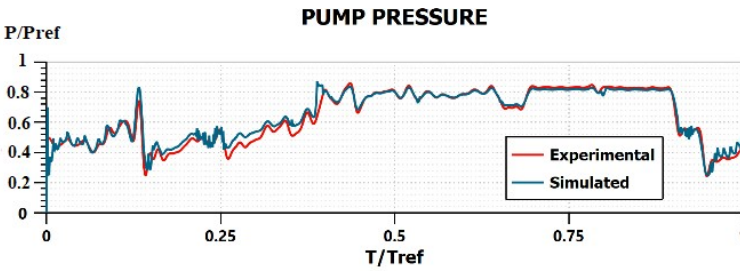

PUMP LS PRESSURE

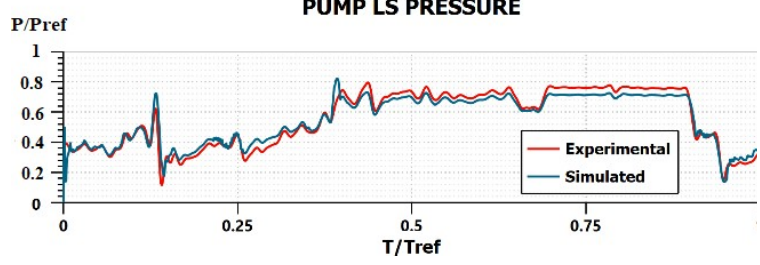

(a)

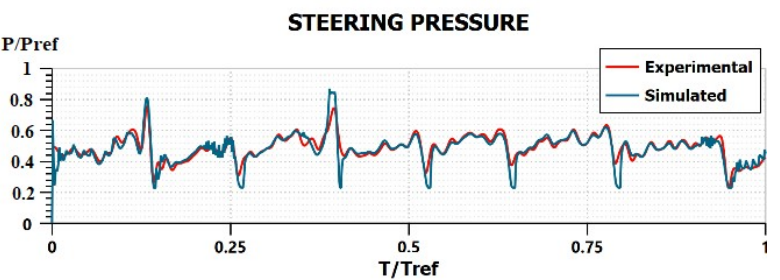

REAR REMOTE PRESSURE

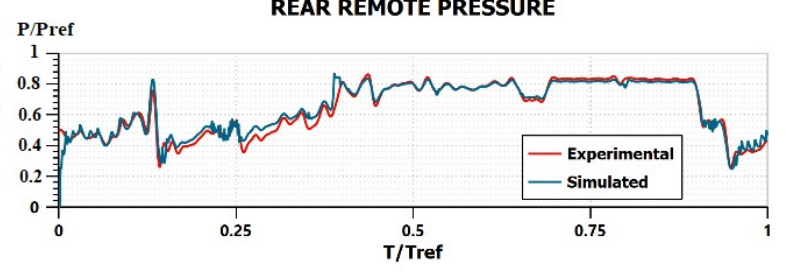

(b)
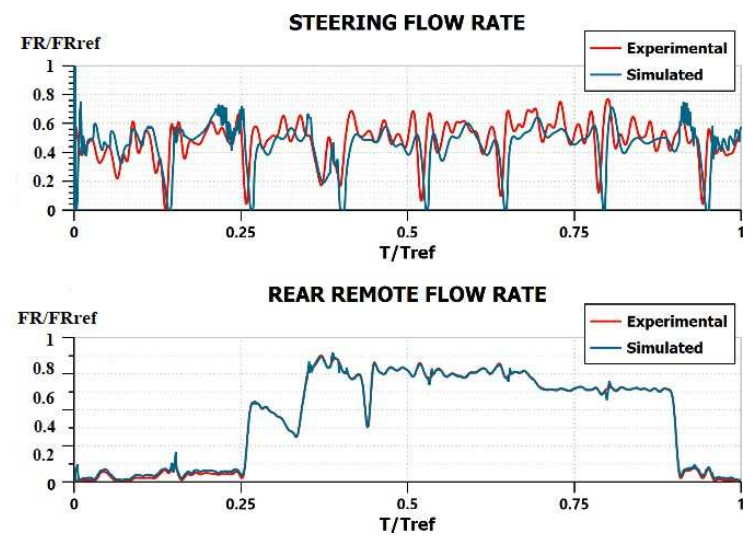

(c)

Fig. 4. Correlation between Experimental (red) and Simulation (blue) results, End-Field Test. (a) pump pressure and pump LS pressure, (b) steering pressure and rear remote pressure, (c) flow rate steering and flow rate rear remote.

Table 1. Hydraulic energy distribution in the hydraulic circuit

\begin{tabular}{|c|c|c|c|c|c|}
\hline $\begin{array}{c}\text { Lines Priority } \\
\text { Valve }\end{array}$ & $\begin{array}{c}\text { Hydraulic } \\
\text { Energy User } \\
\text { E/E E }\end{array}$ & $\begin{array}{c}\text { Hydraulic Energy } \\
\text { Actuator } \\
\text { E/E }_{\text {ref }}\end{array}$ & $\begin{array}{l}\text { Losses through } \\
\text { Steering } \\
\text { E/E } \text { E }_{\text {ref }}\end{array}$ & $\begin{array}{c}\text { Losses through } \\
\text { EHR } \\
\text { E/E } \text { Eef }^{\text {ref }}\end{array}$ & $\begin{array}{c}\text { Losses through } \\
\text { Priority Valve } \\
\text { E/E्Eref }\end{array}$ \\
\hline$P$ & 1 & & & & \multirow[b]{3}{*}{0.12} \\
\hline ST & 0.26 & 0.18 & 0.08 & & \\
\hline $\mathrm{EF}$ & 0.62 & 0.35 & & 0.27 & \\
\hline
\end{tabular}

\section{Alternative solution proposed}

\subsection{Circuit with Load Sensing signal conditioner (LS $\left.{ }_{c}\right)$}

A new device to manage the LS signal has been developed by Walvoil S.p.A [34], and Fig. 5 shows the ISO scheme of the device. This device can be easily installed in the standard circuit leading to control of the effective pressure drop across the valves, leaving unchanged the pressure regulator of the pump.

This device receives the LS signal as input and returns at the output a modified signal called conditioned load sensing LSc. The LSc signal could be either equal, lower or higher than the LS signal, and then the pump adds a constant pump margin value thus determining a pressure drop changed at the distributor cursor.

The device consists of two 3/2 proportional valves: one valve, called main stage, has four hydraulic pilot areas and a spring, the second one, pilot stage is actuated by a solenoid. The system works as a copier, leaving unchanged the LS signal LS=LSc, when the pressure acting on the pilot area A2 balance the force of the spring, therefore also the pressure on the equal pilot area A3 and A1 must be equal to reach the equilibrium. 


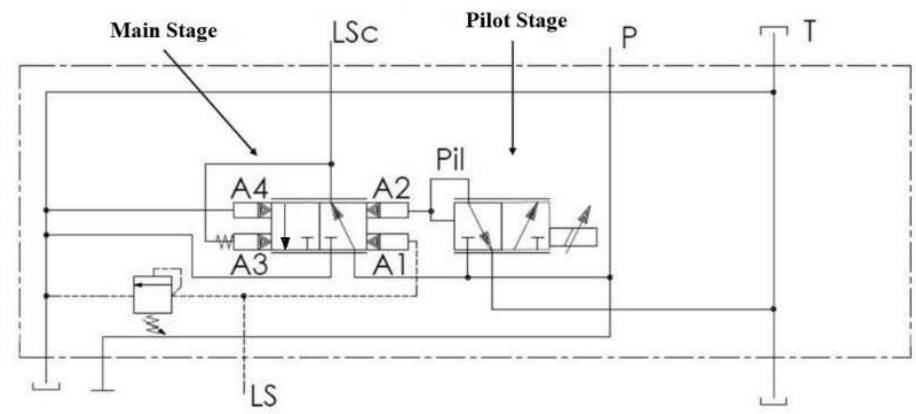

Fig. 5. ISO scheme of the load sensing conditioner

Increasing the pilot pressure, changing the current to the solenoid, the equilibrium of the valve is reached only with LSc pressure is higher than LS pressure, the increment is due to partial connection to the pump line. Vice versa when the pilot pressure is reduced. The LS signal conditioner is actuated with an electrical signal that acts the pilot stage; a dynamic control of this device is possible on the basis of information collected through the circuit. The Fig. 6a shows the LS signals of the two users. The intervention of the conditioner, assuming a LS pressure reduction, occurs only when the LS signal of the rear remotes exceeds of a defined value the load sensing of the steering that is a priority user, in this way the steering system is not affected by this reduction. As reported in Fig. 6b, the intervention of the LS conditioner starts when the LS remote pressure exceeds the LS steering pressure by a certain value. In this way, the steering continues to work maintaining the same pressure drop across its control valve, while the rear remotes work with a smaller pressure drop, to guarantee the required flow rate the spool will result more open. By reducing the LS signal, it is possible to obtain a reduction of the energy consumption compared to the standard circuit; the results are reported in Table 2. The energy consumption of the steering is roughly the same as the standard case, since it is regulated by priority valve main spool that keep the same pressure drop across the steering valve. On the EF line, the energy demand is now 0.57, lower respect the standard case. Furthermore, the losses in the transition to the rear remotes actuator also decrease by about 0.05 due to the reduction of the pressure drop across the valve. Finally, the losses through the priority valve are reduced compared to the standard case, of 0.02 .

Table 2. Hydraulic energy distribution in the hydraulic circuit with LS signal conditioner

\begin{tabular}{|c|c|c|c|c|c|}
\hline $\begin{array}{c}\text { Lines Priority } \\
\text { Valve }\end{array}$ & $\begin{array}{c}\text { Hydraulic } \\
\text { Energy User } \\
\text { E/Eref }\end{array}$ & $\begin{array}{c}\text { Hydraulic Energy } \\
\text { Actuator } \\
\text { E/Eref }\end{array}$ & $\begin{array}{c}\text { Losses through } \\
\text { Steering } \\
\text { E/Eref } \\
\end{array}$ & $\begin{array}{c}\text { Losses through } \\
\text { EHR } \\
\text { E/E } \\
\end{array}$ & $\begin{array}{c}\text { Losses through } \\
\text { Priority Valve } \\
\text { E/Eref } \\
\end{array}$ \\
\hline $\mathrm{P}$ & 0.93 & & & & \multirow[b]{3}{*}{0.10} \\
\hline ST & 0.26 & 0.18 & 0.08 & & \\
\hline $\mathrm{EF}$ & 0.57 & 0.35 & & 0.22 & \\
\hline
\end{tabular}

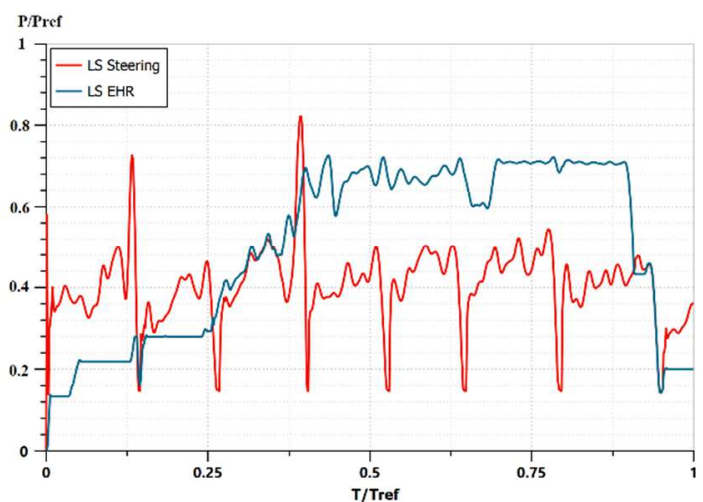

(a)

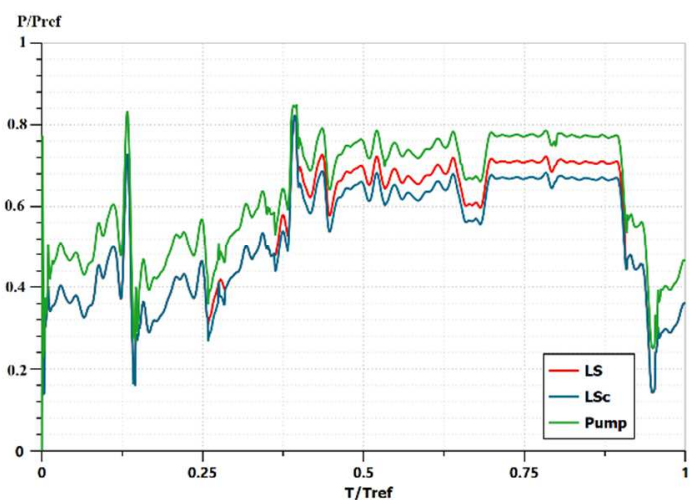

(b)

Fig. 6. (a) LS steering and LS EHR, (b) Intervention of LS signal conditioner 


\subsection{Circuit with Electro-Hydraulic Steering (EHS)}
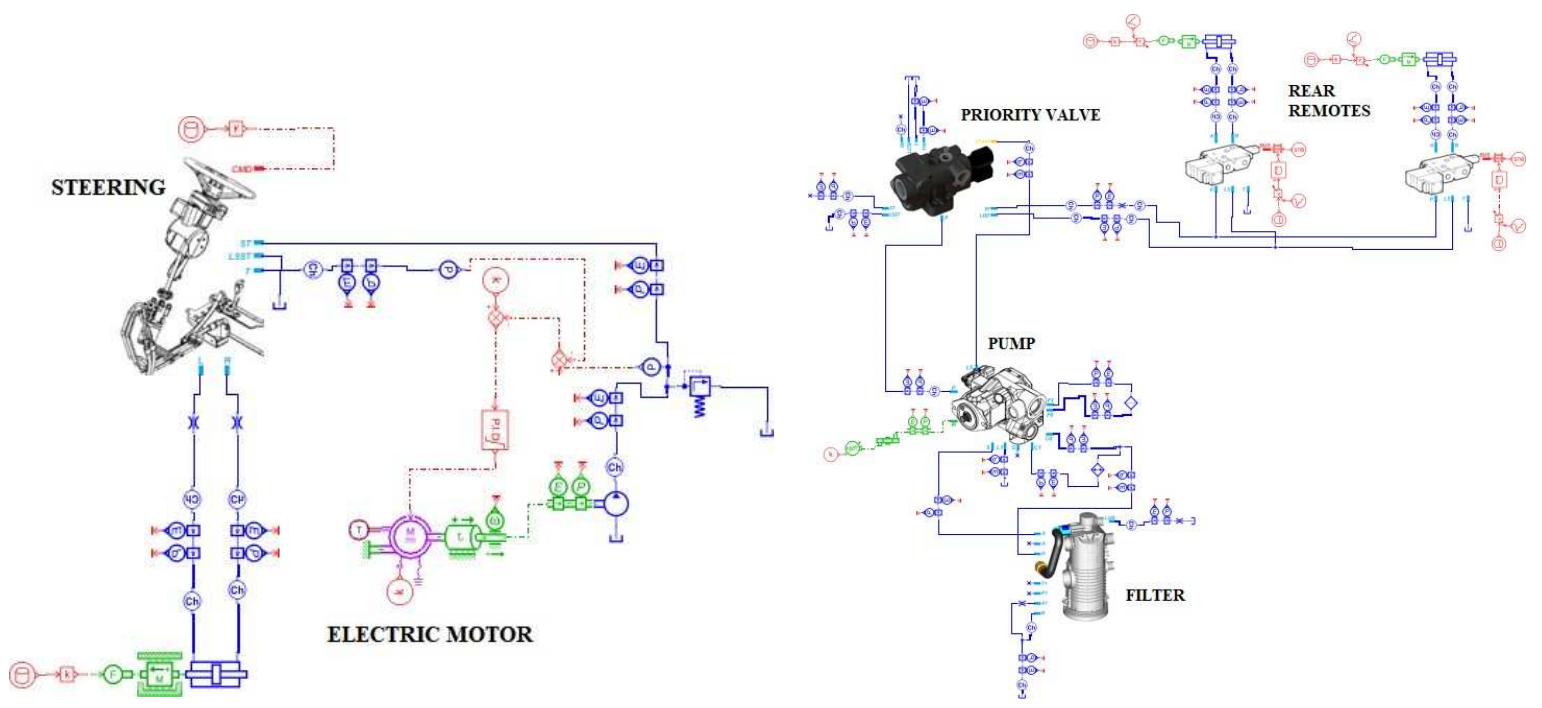

Fig. 7. AMESim ${ }^{\odot}$ sketch of the circuit with electro-hydraulic steering (EHS)

To separate the users a new architecture has been studied, it concerns the separation of the steering from the traditional circuit; so, the losses are reduced because of the main spool of the priority valve is not more crossed by the flow, and the intervention of the pressure compensators are reduced.

The new solution includes electro-hydraulic steering, obtained by controlling the steering with an electric motor that powers a fixed displacement gear pump (Pst), the EHS has been modelled in AMESim $^{\circledR}$ environment as shown in Fig. 7.

The control logic is still a LS logic that regulates the torque and speed of the electric motor ensuring the correct flow rate requested by the steering. This work aims to study only the energy saving advantages of this solution; issues concerning technical assessments on the safety of this system have not been considered.

In table 3 the results obtained with this new configuration shown a reduction of the energy supplied by the pumps, in this configuration there are two pumps in the circuit, the previous pump and one more for the steering. The hydraulic energy supplied by these two pumps is 0.91 ; lower than 1 of the STD case. The losses through the priority valve are now reduced from 0.12 to 0.03 .

Table 3. Hydraulic energy distribution in the circuit with electro-hydraulic steering

\begin{tabular}{|c|c|c|c|c|c|}
\hline $\begin{array}{c}\text { Lines Priority } \\
\text { Valve }\end{array}$ & $\begin{array}{c}\text { Hydraulic Energy } \\
\text { User } \\
\text { E/Eref }\end{array}$ & $\begin{array}{c}\text { Hydraulic Energy } \\
\text { Actuator } \\
\text { E/Eref } \\
\end{array}$ & $\begin{array}{c}\text { Losses through } \\
\text { Steering } \\
\text { E/Eref } \\
\end{array}$ & $\begin{array}{c}\text { Losses through } \\
\text { EHR } \\
\text { E/E } \mathbf{E}_{\text {ref }} \\
\end{array}$ & $\begin{array}{c}\text { Losses through } \\
\text { Priority Valve } \\
\text { E/Eref } \\
\end{array}$ \\
\hline $\mathrm{P}+\mathrm{Pst}$ & 0.91 & & & & \multirow[b]{3}{*}{0.03} \\
\hline ST & 0.27 & 0.18 & 0.09 & & \\
\hline $\mathrm{EF}$ & 0.61 & 0.36 & & 0.25 & \\
\hline
\end{tabular}

To obtain energy savings in relation to users, the LS signal conditioner has been inserted in this circuit (EHS LSc architecture). Results are reported in Table 4; also, in this case the energy consumption on the EF line was reduced thanks to the reduction of the pressure drop through the EHR valve.

The priority valve presents lower pressure losses respect the standard case thanks to the unused main spool, while the total pressure losses remain the same, 0.03 , respect the case of table 3 because the flow rate that cross the secondary spool of the priority valve toward the EHR valve is always the same, to comply with the duty cycle.

In Fig. 8 the results obtained for each configurations are compared. The best solution obtained is the EHS LSc because it presents the advantages of both the LS signal conditioner and the electro-actuated steering. This architecture lowers the losses through the rear remotes reducing the pressure drop and reduces the losses through the priority valve. 
Table 4. Hydraulic energy distribution in the circuit with electro-hydraulic steering and with LS signal conditioner

\begin{tabular}{|c|c|c|c|c|c|}
\hline $\begin{array}{c}\text { Lines Priority } \\
\text { Valve }\end{array}$ & $\begin{array}{c}\text { Hydraulic } \\
\text { Energy User } \\
\text { E/Eref }\end{array}$ & $\begin{array}{c}\text { Hydraulic Energy } \\
\text { Actuator } \\
\text { E/Eref }\end{array}$ & $\begin{array}{c}\text { Losses through } \\
\text { Steering } \\
\text { E/Eref }\end{array}$ & $\begin{array}{c}\text { Losses through } \\
\text { EHR } \\
\text { E/Eref }\end{array}$ & $\begin{array}{c}\text { Losses through } \\
\text { Priority Valve } \\
\text { E/Eref }\end{array}$ \\
\hline P+Pst & 0.85 & & & & \\
\hline ST & 0.26 & 0.18 & 0.08 & & 0.03 \\
\hline EF & 0.56 & 0.34 & & 0.22 & 0.03 \\
\hline
\end{tabular}

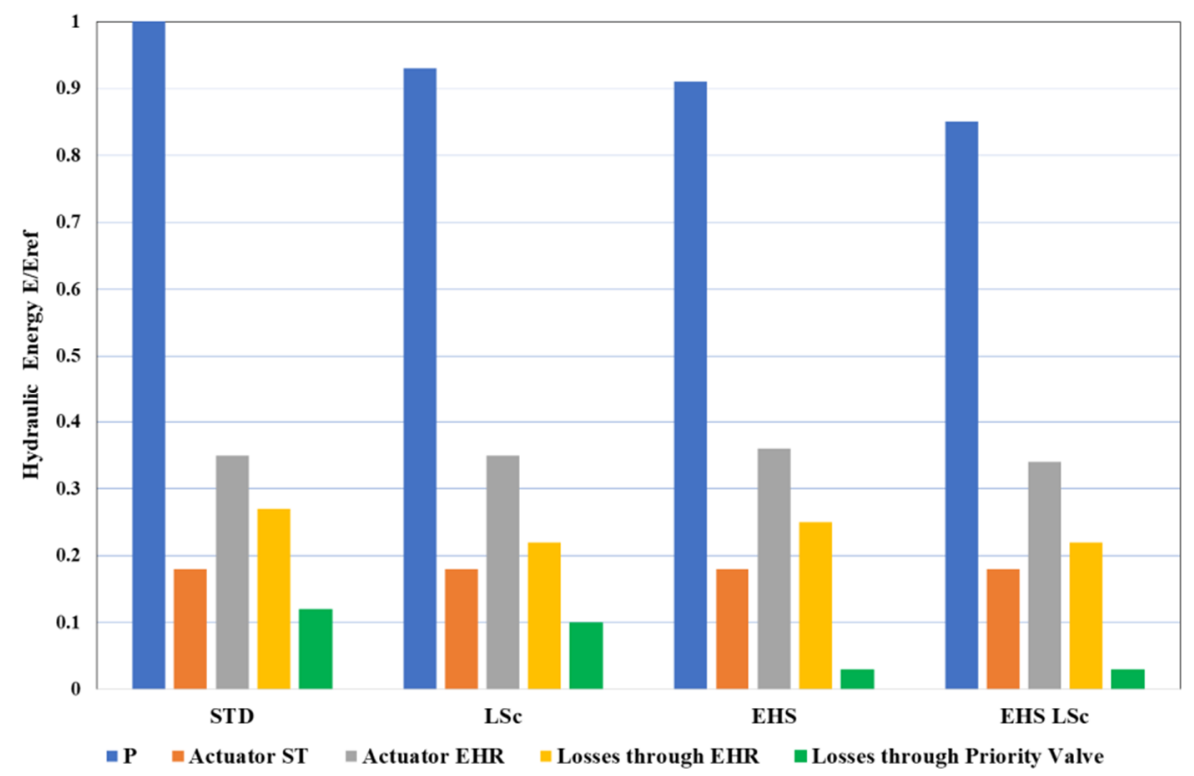

Fig. 8. Hydraulic energy distribution for all the architectures analyzed

\section{Conclusion}

This paper is focused on an energy analysis of the hydraulic circuit of a medium-sized agricultural tractor. The objective of the work has been to evaluate the energy losses of the standard architecture by referring mainly to an effective duty cycle performed by the tractor (End-Field test), and to study alternative solutions that would allow a reduction of energy losses. Two types of alternative architectures have been presented and analyzed. The first architecture presents a LS signal conditioner, it reduces the pressure drop across the valves and it could be dynamically controlled to optimize the energy consumption. The other solution presented is the separation of the steering from the standard circuit and the actuation of the steering with an electric motor that powers a fixed displacement pump. This configuration permits to reduce the losses through the priority valve and, in a LS system, the reduction of the losses through the pressure compensators of the other valves. The combination of the LS signal conditioner with the electro-actuated steering has presented the best advantage in terms of energy savings.

Acknowledgments: The authors would like to acknowledge BSIM (Italy) for the support to the Simcenter AMESim $^{\circledR}$ software.

Funding: This research has been funded by POR FESR 2014-2020 “TASC - Trattrici Agricole Smart \& Clean”.

\section{Nomenclature}

$\begin{array}{ll}E & \text { Energy } \\ E_{r e f} & \text { Energy Reference } \\ E F & \text { Other Users line } \\ E H R & \text { Electro-Hydraulic Remote } \\ E H S & \text { Electro-Hydraulic Steering } \\ L S & \text { Load Sensing } \\ L S_{c} & \text { Load Sensing Conditioner }\end{array}$

LVDT Linear Variable Displacement Transducer

$M S \quad$ Main Spool Priority Valve

$P \quad$ Main Pump

$P_{s t} \quad$ Steering Pump

SS Secondary Spool Priority valve

ST Steering line

STD Standard 


\section{References}

1. M. Vukovic, R. Leifeld, H. Murrenhoff, Reducing Fuel Consumption in Hydraulic Excavators-A Comprehensive Analysis. 2017 Energies 10.5, p. 687. doi: 10.3390/en10050687.

2. M. Inderelst, F.D. Weidner, C. Stammen, Quantification of Energy Saving Influencers. 21t Excavator Hydraulic System - A Holistic Investigation? 2018, 11th International Fluid Power Conference 19th 21th March

3. Joo, C., Stangl, M. Application of Power Regenerative Boom system to excavator. 2016 In Proceedings of the 10. IFK: International Fluid Power Conference, Dresden, Germany, 8-10 March; Volume 3, pp. 175-184;

4. Li, J.; Zhao, J.; Zhang, X. A Novel Energy Recovery System Integrating Flywheel and Flow Regeneration for a Hydraulic Excavator Boom System. Energies 2020,13, 315. DOI: 10.3390/en13020315.

5. Guan, C. \& Xu, X. \& Lin, X. \& Wang, S.-H. Recovering system of swing braking energy in hydraulic excavator. Zhejiang Daxue Xuebao (Gongxue Ban)/Journal of Zhejiang University (Engineering Science) 2012. 46. 142-149. DOI: 10.3785/j.issn.1008-973X.2012.01.23.

6. P. Casoli, A. Gambarotta, N. Pompini, L. Riccò. Development and application of co-simulation and control-oriented modeling in the improvement of performance and energy saving of mobile machinery. Energy Procedia, Volume 45, 2014, Pages 849-858. Elsevier. doi:10.1016/j.egypro.2014.01.090.

7. P. Casoli, A. Anthony, L. Riccò. Modeling of an Excavator System - Load sensing flow sharing valve model. SAE 2012 Commercial Vehicle Engineering Congress, Rosemont, Illinois, USA, 13-14 September 2012. doi:10.4271/2012-01-2042.

8. P. Casoli, A. Gambarotta N. Pompini, L. Riccò. Coupling excavator hydraulic system and internal combustion engine models for the Real-Time simulation. Control Engineering Practice 2015, pp. 26-37. DOI: 10.1016/j.conengprac.2015.04.003.

9. P. Casoli, N. Pompini, L. Riccò. Simulation of an Excavator Hydraulic System Using Nonlinear Mathematical Models. Strojniški vestnik - Journal of Mechanical Engineering 61 (2015)10, 583-593. DOI:10.5545/sv-jme.2015.2570

10. Bedotti, A., Campanini, F., Pastori, M., Riccò, L., Casoli, P. Energy saving solutions for a hydraulic excavator. Energy Procedia 2017, 126, pp. 1099-1106 DOI: 10.1016/j.egypro.2017.08.255

11. Paolo Casoli, Luca Riccò, Federico Campanini, Andrea Bedotti. Hydraulic Hybrid ExcavatorMathematical Model Validation and Energy Analysis, Energies 2016, 9, 1002; doi:10.3390/en9121002

12. P. Casoli, A. Anthony, M. Rigosi. Modeling of an Excavator System - Semi empirical hydraulic pump model" SAE - International Journal of Commercial Vehicles October 2011 vol. 4, Issue 1, pp. 242- 255. ISSN: 1946-391X. doi:10.4271/2011-01-2278.

13. P. Casoli, L. Riccò, F. Campanini, A. Lettini, C. Dolcin. Mathematical model of an hydraulic excavator for fuel consumption predictions" Proceedings of the ASME/BATH Symposium on Fluid Power \& Motion Control FPMC2015 October 12-14, 2015, Chicago, Illinois, United States ISBN: 978-0-79185723-6. Paper No. FPMC2015-9566, pp. V001T01A035; 10 pages. doi:10.1115/FPMC2015-9566

14. Rundo M. Models for Flow Rate Simulation in Gear Pumps: A Review, Energies 2017 10(9), 1261, 2017; DOI:10.3390/en10091261.

15. Zardin, B.; Natali, E.; Borghi, M. Evaluation of the Hydro-Mechanical Efficiency of External Gear Pumps. Energies 2019, 12, 2468. https://doi.org/10.3390/en12132468

16. E. Frosina, D. Buono, A. Senatore, I. J. Costin. A Simulation Methodology Applied on Hydraulic Valves for High Fluxes. International Review on Modelling and Simulations 2016 9(3):217, doi: 10.15866/iremos.v9i3.9612.

17. E. Frosina, A. Senatore, M. Rigosi. Study of a High-Pressure External Gear Pump with a Computational Fluid Dynamic Modeling Approach. Energies 2017, 10(8), pp. 1113 - 1133

18. Altare G., Rundo M. CFD Analysis of gerotor lubricating pumps at high speed: geometric features influencing the filling capability. Proceedings of the ASME/BATH 2015 Symposium on Fluid Power and Motion Control (FPMC), Oct. 12-14, 2015, Chicago, IL, USA. Paper no. FPMC2015-9539. DOI: 10.1115/FPMC2015-9539. 
19. P. Casoli, A. Anthony. Gray box modeling of an excavator's variable displacement hydraulic pump for fast simulation of excavation cycles. Control Engineering Practice 212013 pp.483-494. Elsevier Ltd. doi:/10.1016/j.conengprac.2012.11.011.

20. Zardin, B., Borghi, M., Cillo, G., Rinaldini, C.A., Mattarelli, E., Design Of Two-Stage On/Off Cartridge Valves For Mobile Applications, Energy Procedia, Volume 126, 2017, Pages 1123-1130, ISSN 18766102, https://doi.org/10.1016/j.egypro.2017.08.275

21. Padovani, D., Rundo, M., Altare, G. The Working Hydraulics of Valve-Controlled Mobile Machines: Classification and Review. J. Dyn. Sys., Meas., Control 2020, 142(7), 070801. DOI:10.1115/1.4046334.

22. J. Rosero, J. Ortega, E. Aldabas and L. Romeral. Moving Towards a more Electric Aircraft. IEEE A\&E System Magazine, 2007 pp. 3-9, March. DOI: 10.1109/MAES.2007.340500

23. M. Schneider, O. Koch, and J. Weber. Green Wheel Loader - improving fuel economy through energy efficient drive and control concepts. 10th Int. Fluid Power Conf., Dresden, 2016.

24. S. Smith, J. Irving and J. Irving. Electro Hydrostatic Actuators for Control of Undersea Vehicles. Joint Undersea Warfare Technology Fall Conference, 2006 Groton, Connecticut.

25. Schmidt, L., Ketelsen, S., Brask, M.H., Mortensen, K.A. A Class of Energy Efficient Self-Contained Electro-Hydraulic Drives with Self-Locking Capability. Energies 2019, 12, 1866, doi:10.3390/en12101866.

26. Padovani D., Ketelsen S., Hagen D., Schmidt L. A Self-Contained Electro-Hydraulic Cylinder with Passive Load-Holding Capability. Energies 2019, 12, 292 doi:10.3390/en12020292.

27. Ketelsen S., Padovani D., Andersen T.O., Ebbesen M.K., Schmidt L. Classification and Review of Pump-Controlled Differential Cylinder Drives. Energies 2019, 12. 1293. DOI:10.3390/en12071293

28. Casoli P., Vacca A., Anthony A., Berta G.L. Numerical and Experimental Analysis of the Hydraulic Circuit for the Rear Hitch Control in Agricultural Tractors. $7^{\text {th }}$ International Fluid Power Conference, (pp. 51-63, vol. 1) Aachen, 22-24/03 2010, ISBN 978-3-940565-90-7

29. Pintore F, Borghi M, Morselli R, Benevelli A, Zardin B, Belluzzi F. Modelling and Simulation of the Hydraulic Circuit of an Agricultural Tractor. ASME. Fluid Power Systems Technology 2014, 8th FPNI Ph.D Symposium on Fluid Power:V001T04A004. doi:10.1115/FPNI2014-7848. Conference, (pp. 5163, vol. 1) Aachen, 22-24/03 2010, ISBN 978-3-940565-90-7

30. Borghi, M., Zardin, B., Pintore, F., Belluzzi, F. Energy Savings in the Hydraulic Circuit of Agricultural Tractors, Energy Procedia, Volume 45, 2014, Pages 352-361, ISSN 1876-6102, https://doi.org/10.1016/j.egypro.2014.01.038.

31. Panetta, G., Mancarella, F., Borghi, M., Zardin, B., and Pintore, F., Dynamic Modelling of an Off-Road Vehicle for the Design of a Semi-Active, Hydropneumatic Spring-Damper System. Proceedings of the ASME 2015 International Mechanical Engineering Congress and Exposition. Volume 4B: Dynamics, Vibration, and Control. Houston, Texas, USA. November 13-19, 2015. V04BT04A006. ASME. https://doi.org/10.1115/IMECE2015-51615

32. Zardin, B.; Borghi, M.; Gherardini, F.; Zanasi, N. Modelling and Simulation of a Hydrostatic Steering System for Agricultural Tractors. Energies 2018, 11, 230. https://doi.org/10.3390/en11010230

33. M.Borghi, B. Zardin, F. Belluzzi, F. Pintore, Energy Savings in the Hydraulic Circuit of Agricultural Tractors, Energy Procedia 45 (2014), pp. 352 - 361. https://doi.org/10.1016/j.egypro.2014.01.038.

34. Patent pending US2020124194 